\title{
No significant long-term complications from inadvertent exposure to gonadotropin-releasing hormone agonist during early pregnancy in mothers and offspring: a retrospective analysis
}

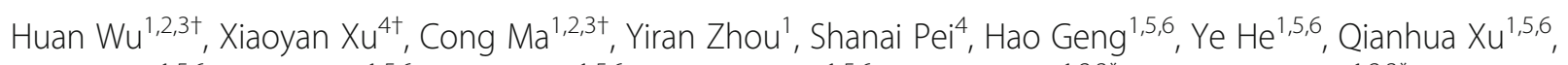
Yuping $X u^{1,5,6}$, Xiaojin $\mathrm{He}^{1,5,6}$, Ping Zhou ${ }^{1,5,6}$, Zhaolian Wei ${ }^{1,5,6}$, Xiaofeng $X u^{1,2,3^{*}}$ and Yunxia Cao $1,2,3^{*}$

\begin{abstract}
Background: Administration of gonadotropin-releasing hormone agonist ( $\mathrm{GnRH}-\mathrm{a})$ in the luteal phase is commonly used for pituitary suppression during in vitro fertilisation (IVF). There is an ineluctable risk of inadvertent exposure of spontaneous pregnancy to $\mathrm{GnRH}-\mathrm{a}$. However, little is known about the pregnancy complications and repregnancy outcomes of the affected women and the neurodevelopmental outcomes of the GnRH-a-exposed children.

Methods: Retrospective analysis was used to determine obstetric and repregnancy outcomes after natural conception in 114 women who naturally conceived while receiving GnRH-a during their early pregnancy over the past 17 years. The GnRH-a-exposed children were evaluated to determine their neonatal characteristics and longterm neurodevelopmental outcomes. The outcomes were compared to those of relevant age-matched control groups.
\end{abstract}

Results: Sixty-five women had 66 live births. The neonatal health outcomes and the incidence of maternal complications were similar in the GnRH-a-exposed and control groups. Thirty-one $\mathrm{GnRH}$-a-exposed children, aged 2-8years, were available for investigation of neurodevelopment. Except for one case of autism spectrum disorder, the full-scale intelligence quotient score was within the normal range and similar to that of the control group. Most mothers with successful pregnancies and about one-third of the women who had spontaneous abortions were subsequently able to conceive naturally again. IVF is recommended for repregnancy in women who have experienced ectopic pregnancies.

(Continued on next page)

\footnotetext{
*Correspondence: xxf0550@126.com; caoyunxia6@126.com

${ }^{\dagger}$ Huan Wu, Xiaoyan Xu and Cong Ma contributed equally to this work. 'Reproductive Medicine Center, Department of Obstetrics and Gynecology, The First Affiliated Hospital of Anhui Medical University, No. 218 Jixi Road, Hefei 230022, China

Full list of author information is available at the end of the article
}

(c) The Author(s). 2021 Open Access This article is licensed under a Creative Commons Attribution 4.0 International License, which permits use, sharing, adaptation, distribution and reproduction in any medium or format, as long as you give appropriate credit to the original author(s) and the source, provide a link to the Creative Commons licence, and indicate if changes were made. The images or other third party material in this article are included in the article's Creative Commons licence, unless indicated otherwise in a credit line to the material. If material is not included in the article's Creative Commons licence and your intended use is not permitted by statutory regulation or exceeds the permitted use, you will need to obtain permission directly from the copyright holder. To view a copy of this licence, visit http://creativecommons.org/licenses/by/4.0/. The Creative Commons Public Domain Dedication waiver (http://creativecommons.org/publicdomain/zero/1.0/) applies to the data made available in this article, unless otherwise stated in a credit line to the data. 
(Continued from previous page)

Conclusions: Accidental exposure to $\mathrm{GnRH}-\mathrm{a}$ in early pregnancy might be safe. Reproductive treatment

suggestions for repregnancy should be made with consideration of the outcomes of the previously $\mathrm{GnRH}$-a-

exposed spontaneous pregnancy.

Keywords: Gonadotropin-releasing hormone agonist, Neurodevelopment, Obstetric outcomes, Repregnancy, Teratogenicity

\section{Background}

Gonadotropin-releasing hormone agonist (GnRH-a) has been commonly used as a hypothalamic regulator for controlled ovarian stimulation (COS) in the cycle of in vitro fertilisation (IVF) [1]. The GnRH analogue is characterised by substitution of a D-amino acid for the glycine at position six of GnRH. This structural modification increases its affinity for the $\mathrm{GnRH}$ receptor and enhances its resistance to proteolytic degradation [2]. As one of the mainstream regimes for $\operatorname{COS}[1,3,4]$, the $\mathrm{GnRH}-\mathrm{a}$ long protocol reduces the cancellation rates of $\mathrm{COS}$, which is usually caused by premature luteinisation and spontaneous ovulation [5], and increases the number of retrieved oocytes as well as the clinical pregnancy rates $[6,7]$. However, there is an ineluctable risk of inadvertent exposure of pregnancy to $\mathrm{GnRH}$-a administered in the luteal phase of the conception cycle [8].

Several studies have reported no significantly abnormal outcomes of such spontaneous pregnancies that have involved accidental exposure to $\mathrm{GnRH}$-a during COS [9-15]. Furthermore, some infertile patients could become pregnant repeatedly with the administration of GnRH-a [16-19]. These observations seem to indicate that the occurrence of these unexpected pregnancies is not merely coincidental, but that $\mathrm{GnRH}-\mathrm{a}$ might play a positive role in promoting fertility. This hypothesis is strongly supported by the extrahypothalamic activities of $\mathrm{GnRH}$, which is involved in reproductive processes at multiple levels. GnRH has been demonstrated to play a crucial role in improving the development of mammalian blastocysts [20-22], stimulating embryonic trophoblastic cell invasion [23, 24], inducing placental secretion of human chorionic gonadotropin (HCG) [25-27], and regulating the receptivity of the uterine endometrium to the embryo $[28,29]$. Accumulating evidence of these advantages has led to the deliberate adoption of GnRH-a in some IVF cycles to promote embryo implantation, sometimes with positive results [30-32].

Although most of the individuals with GnRH-aexposed pregnancy could give birth to healthy offspring, and the incidence of miscarriage and malformation in such cohorts was not significantly different from that in the general population [18], most follow-up studies were based only on early postnatal examination of the infants. Reports evaluating the long-term neurological outcomes of these affected children are quite rare $[19,33]$. Therefore, a long-term follow-up survey is crucial for elucidating the potential impact of this $\mathrm{GnRH}$ analogue on foetation.

The current study retrospectively analysed the maternal complications and neonatal health outcomes of a large cohort of women in China who had experienced $\mathrm{GnRH}-\mathrm{a}$ administration during early pregnancy over the past 17 years, and evaluated the long-term neurodevelopmental outcomes of their offspring. Furthermore, we investigated these women's repregnancy outcomes. This long-term follow-up survey would provide insight into the effects of GnRH-a on early pregnancy and provide a basis for appropriate counselling of such patients on reproductive treatment.

\section{Methods}

\section{Study population}

Women who were inadvertently exposed to GnRH-a soon after conception in the Reproductive Medicine Center of the First Affiliated Hospital of Anhui Medical University from January 2003 to December 2019 were enrolled in this study. These couples had planned to undergo IVF due to infertility of various aetiologies, such as tubal damage, male factors, and recurrent spontaneous abortion (RSA). A long protocol of pituitary desensitisation was performed on days 21-23 of the previous cycle, either with a daily dose of $0.1 \mathrm{mg}$ short-acting GnRH-a (Triptorelin, $0.1 \mathrm{mg}$; Ferring Pharma, Kiel, Germany) for 14 days, or with a single dose of 0.9-1.1 mg long-acting GnRH-a (Triptorelin, $3.75 \mathrm{mg}$; Beaufour Ipsen Pharma, Paris, France). The $3.75 \mathrm{mg}$ triptorelin was mixed with $2 \mathrm{ml}$ sterile water beforehand. The 0.48 $0.59 \mathrm{ml}$ solution containing $0.9-1.1 \mathrm{mg}$ triptorelin was subsequently aspirated with a $1 \mathrm{ml}$ sterile syringe for injection. The single dose of long-acting GnRH-a was adjusted according to the patients' weight.

Couples were not advised to use contraceptive precautions during this downregulation phase but were informed that an inadvertent pregnancy could occur. Unexpected pregnancies were identified by routine assay of serum $\beta$-HCG on the 14th day after initiation of GnRH-a administration. Each couple chose to continue with the inadvertent pregnancy. Progesterone in oil was subsequently injected up to the 10th 
gestational week, at a dose of $40-60 \mathrm{mg}$ per day. Clinical pregnancy was confirmed by transvaginal ultrasound 6 weeks after the occurrence of the last menses.

Available children who had been born to mothers who were exposed to $\mathrm{GnRH}-\mathrm{a}$ during early pregnancy were also assessed through face-to-face interaction. In addition, two groups of age-matched children, born in our hospital, were included as control groups. One group contained 45 children who were born as the result of IVF, and the other group comprised 45 children who were born after spontaneous pregnancies.

All participants provided signed informed consent after an explanation of the study; furthermore, all parents of the children gave consent for their offspring to participate in the study. The research protocol was approved by the ethics committee of Anhui Medical University.

\section{Retrieval of medical records of obstetric characteristics and collection of repregnancy outcomes}

Information regarding maternal complications, such as preterm delivery, gestational hypertension, gestational diabetes, placenta previa, and postpartum haemorrhage, was retrospectively analysed using the women's hospital charts. We also reviewed the neonatal characteristics of the offspring, including mode of delivery, gestational age, birth weight, body height, Apgar score, and birth defects. Moreover, the repregnancy outcomes of these women were meticulously collected by telephonic follow-up.

\section{Investigation of the physical health and} neurodevelopment of the affected children

The general physical health of all children was assessed by the same paediatrician. The Wechsler Preschool and Primary Scale of Intelligence-4th edition (WPPSI-IV, Chinese version) was used to investigate the neurodevelopment of all children aged 28 years. The Full-Scale Intelligent Quotient (FSIQ) score was calculated to represent the child's intellectual abilities. Children with suspected impairments in social or executive functioning were more closely examined. Attention-deficit hyperactivity disorder (ADHD) and autism spectrum disorders (ASDs) were diagnosed based on the criteria of the Diagnostic and Statistical Manual of Mental Disorders-5th edition.

\section{Statistical analyses}

Measurement data with a normal distribution are described using mean \pm standard deviation, and count data are described using frequency and percentage. Student's $t$-test was used to compare the means between two groups. Chi-square tests were used to compare proportions between the two groups. One-way analysis of variance was used to compare means among the three groups. $P$-values $\leq 0.05$ indicated statistically significant differences. Statistical analyses were conducted using SPSS (Windows version 16.0, IBM-SPSS, Chicago, IL).

\section{Results}

Clinical data and pregnancy outcomes after inadvertent exposure to GnRH-a soon after conception

Among 26,002 IVF cycles conducted with GnRH-a long protocol at our centre over the past 17 years, $146(0.56 \%)$ resulted in clinical pregnancy during the administration of GnRH-a. The number of annual GnRH-a long protocol-associated IVF cycles and the corresponding spontaneous conception cases involving exposure to GnRH-a are summarised in Fig. S1. Follow-up surveys were available for 114 (78.08\%) mothers. Clinical data of the initial 146 couples, the 114 couples with follow-up available, and the 32 couples lost to follow-up are presented in Table S1.

Among the 114 women with inadvertent pregnancy, $65(57.02 \%)$ gave birth to 66 children (including one twin pregnancy). Another three (2.63\%) individuals were pregnant at the time of writing this manuscript. The remaining mothers (40.35\%) had to terminate their pregnancies due to ectopic pregnancies $(15.79 \%)$ or spontaneous abortion (24.55\%) (Fig. 1a).

Tubal damage, male factors, and RSA accounted for the initial infertility in 47 (41.23\%), 27 (23.68\%), and 14 $(12.28 \%)$ cases, respectively, and other causes were responsible for infertility in $26(22.81 \%)$ cases (Fig. 1b). The composition of subfertile cases with distinct aetiology according to pregnancy outcome is summarised in Fig. 1c. There were no significant differences between the live birth group and the non-live birth group in terms of the baseline characteristics, such as couples' age, duration of infertility, body mass index, basal sex hormone levels, number of antral follicles, and sperm parameters (Table 1).

\section{Maternal complications of women who gave live birth after inadvertent exposure to $\mathrm{GnRH}-\mathrm{a}$}

The rates of preterm delivery, gestational hypertension, and gestational diabetes among the 65 women who gave live birth after spontaneously conceiving with exposure to GnRH-a were $18.46,4.62$, and $4.62 \%$, respectively. There were no instances of placenta previa or postpartum haemorrhage. Notably, the incidence of these complications in this cohort was comparable to that of the age-matched mothers who had conceived naturally or following IVF (Table S2). 
a

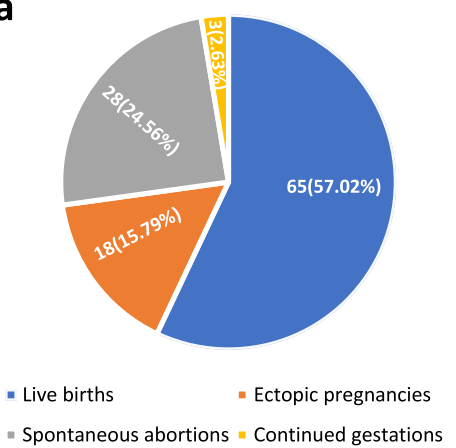

b

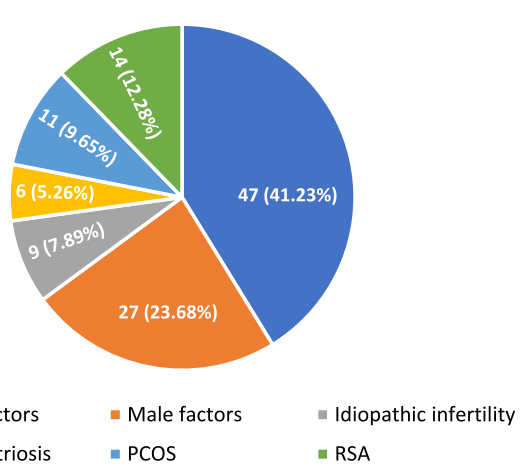

C

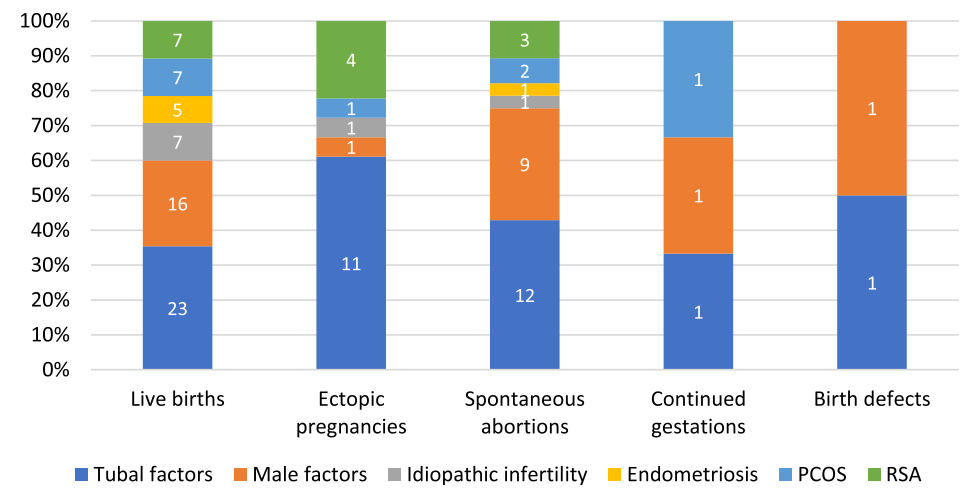

Fig. 1 Observations on etiologic classification and pregnancy outcomes of the involved subjects. a For the 114 GnRH-a-related spontaneous pregnancies that could be followed up, 65 (57.02\%) pregnancies resulted in live births, and another three (2.63\%) pregnancies are ongoing. The remaining 46 (40.35\%) pregnancies were lost as a result of ectopic pregnancy (15.79\%) or spontaneous abortion (24.55\%). b According to etiologic classification, the involved 114 subfertile couples consisted of 47 (41.23\%) tubal damage cases, 27 (23.68\%) sperm disorder cases, 14 (12.28\%) recurrent spontaneous abortion (RSA) cases, 11 (9.65\%) polycystic ovary syndrome (PCOS) cases, 6 (5.30\%) endometriosis cases and 9 (7.89\%) idiopathic infertile cases, respectively. c The subfertile cases with distinct etiologies were calculated separately based on the classification of pregnancy outcome. Tubal damage cases represented the main component in those groups. Furthermore, the proportion of tubal damage cases in ectopic pregnancies (61.11\%) and the group of birth defects (66.67\%) were higher than in other groups

\section{Neonatal characteristics and long-term neurodevelopmental outcomes of children born after exposure to $\mathrm{GnRH}-\mathrm{a}$}

Neonatal health parameters, such as birth weight, body height, and Apgar score, of the 66 children who were born after exposure to $\mathrm{GnRH}-\mathrm{a}$ were all within the normal range. Furthermore, except for one case of ventricular septal defect (VSD) and one case of cleft lip $(\mathrm{CL})$, no other significant malformations occurred (Table S3). The VSD had closed naturally about 6 months after birth, and the CL had been surgically repaired by the age of 2 years.

Of the 66 children, only 31 (46.97\%) children aged 2 to 8 years $(5.03 \pm 1.80)$ were available for investigation of neurodevelopment (Table 2). There was no evidence of any family history that might be associated with mental disorders in this cohort. Only one child was diagnosed with ASD. The general cognitive status was within the normal range in the other children, and their average FSIQ score was $105.77 \pm 8.58$.
In addition, the neonatal health and long-term neurodevelopmental outcomes of the 31 children with GnRHa exposure were compared with those of 45 IVFconceived children and 45 naturally conceived children. One child in the IVF group was diagnosed with an atrial septal defect. The caesarean section rate of the study group was significantly lower than that of the IVF group $(p=0.037)$. There were no statistically significant differences between the study group and the two control groups in terms of gestational weeks, birth weight, body height, and Apgar scores. In terms of neurodevelopmental outcomes, two subjects in the IVF group and one in the spontaneous conception group had ADHD features. The average FSIQ score of the study group were comparable to those of the control groups.

\section{Repregnancy outcomes of the 62 women with GnRH-a- exposed spontaneous pregnancies}

The repregnancy outcomes of the 62 (55.86\%) women who wanted an additional child or desired to become 
Table 1 Clinical characteristics of the couples inadvertently exposed to $\mathrm{GnRH}$-a soon after conception

\begin{tabular}{|c|c|c|c|}
\hline \multirow[t]{2}{*}{ Clinical parameters } & \multicolumn{2}{|c|}{ Couples with unexpected pregnancies associated with GnRH-a $(n=114)$} & \multirow[t]{2}{*}{$P$ value } \\
\hline & Women with live birth $(n=65)$ & Women without live birth $(n=49)$ & \\
\hline \multicolumn{4}{|l|}{ Female general characteristics } \\
\hline Age (y) & $29.02 \pm 3.42$ & $30.06 \pm 3.82$ & 0.127 \\
\hline Duration of infertility (y) & $3.13 \pm 1.90$ & $3.00 \pm 2.49$ & 0.749 \\
\hline Primary infertility cases (\%) & $30(46.15)$ & $26(53.06)$ & 0.465 \\
\hline $\mathrm{BMI}\left(\mathrm{kg} / \mathrm{m}^{2}\right)$ & $21.97 \pm 3.20$ & $21.04 \pm 2.38$ & 0.090 \\
\hline \multicolumn{4}{|l|}{ Basal serum sex hormone levels } \\
\hline FSH (pmol/L) & $6.94 \pm 2.11$ & $7.08 \pm 1.75$ & 0.711 \\
\hline LH (pmol/L) & $5.30 \pm 3.15$ & $4.84 \pm 2.26$ & 0.726 \\
\hline$E_{2}(p m o l / L)$ & $165.71 \pm 133.16$ & $173.99 \pm 112.68$ & 0.171 \\
\hline $\mathrm{T}(\mathrm{pmol} / \mathrm{L})$ & $1.41 \pm 1.34$ & $1.19 \pm 0.46$ & 0.380 \\
\hline PRL (pmol/L) & $16.18 \pm 11.53$ & $19.31 \pm 12.58$ & 0.260 \\
\hline \multicolumn{4}{|l|}{ Number of antral follicles } \\
\hline Right ovary & $5.80 \pm 2.29$ & $5.33 \pm 2.57$ & 0.320 \\
\hline Left ovary & $5.46 \pm 2.46$ & $5.78 \pm 2.31$ & 0.490 \\
\hline \multicolumn{4}{|l|}{ Male characteristics } \\
\hline Age (y) & $30.85 \pm 4.68$ & $31.69 \pm 4.21$ & 0.320 \\
\hline Sperm volume (ml) & $3.52 \pm 1.57$ & $3.70 \pm 1.59$ & 0.542 \\
\hline Sperm concentration $\left(10^{6} / \mathrm{ml}\right)$ & $91.17 \pm 81.43$ & $70.15 \pm 50.38$ & 0.115 \\
\hline Progress motility (\%) & $44.43 \pm 17.57$ & $42.34 \pm 15.08$ & 0.247 \\
\hline Sperm abnormality rate (\%) & $90.33 \pm 43.40$ & $90.78 \pm 43.85$ & 0.433 \\
\hline
\end{tabular}

Annotation: BMI Body mass index, FSH Follicle stimulating hormone, LH Luteinizing hormone, E2 Estradiol, $T$ Testosterone, PRL Prolactin

Table 2 Neonatal characteristics and long-term neurodevelopment outcomes of the 31 children born following exposure to GnRH-a

\begin{tabular}{|c|c|c|c|c|}
\hline Clinical data & $\begin{array}{l}\text { Children born following exposure } \\
\text { to GnRH-a }(n=31)\end{array}$ & $\begin{array}{l}\text { Children born following IVF } \\
(n=45)\end{array}$ & $\begin{array}{l}\text { Children born following spontaneous } \\
\text { conception }(n=45)\end{array}$ & $P$ value \\
\hline \multicolumn{5}{|l|}{ Mode of delivery } \\
\hline $\begin{array}{l}\text { Caesarean } \\
\text { section } \%^{b}\end{array}$ & $40.0(12 / 30)$ & $64.44(29 / 45)$ & $37.78(17 / 45)$ & 0.023 \\
\hline \multicolumn{5}{|c|}{ Neonatal health outcomes } \\
\hline $\begin{array}{l}\text { Gestational } \\
\text { weeks }\end{array}$ & $37.97 \pm 1.89$ & $37.80 \pm 2.37$ & $38.60 \pm 1.84$ & 0.093 \\
\hline Singleton birth & 29 & 33 & 45 & - \\
\hline Twins & 1 & 6 & 0 & - \\
\hline Birth weight (g) & $3175.81 \pm 477.82$ & $3160.00 \pm 405.45$ & $3308.89 \pm 373.15$ & 0.111 \\
\hline $\begin{array}{l}\text { Body height } \\
(\mathrm{cm})\end{array}$ & $50.16 \pm 2.53$ & $49.73 \pm 1.79$ & $50.11 \pm 1.19$ & 0.449 \\
\hline Apgar score & $9.97 \pm 0.18$ & $9.87 \pm 0.34$ & $9.93 \pm 0.25$ & 0.239 \\
\hline Birth defects & 1 (Cleft lip) & 1 (ASD) & 0 & - \\
\hline \multicolumn{5}{|c|}{ Neurodevelopmental outcomes } \\
\hline $\begin{array}{l}\text { Children age } \\
\text { (year) }\end{array}$ & $5.03 \pm 1.80$ & $5.22 \pm 1.99$ & $5.16 \pm 1.15$ & 0.860 \\
\hline $\mathrm{FSIQ}^{\mathrm{a}}$ & $105.77 \pm 8.58$ & $105.98 \pm 10.61$ & $104.60 \pm 11.26$ & 0.865 \\
\hline ADHD & 0 & 2 & 1 & - \\
\hline ASDs & 1 & 0 & 0 & - \\
\hline
\end{tabular}

Annotation: ${ }^{\text {a }}$ the child with ASDs was not evaluated; ${ }^{\mathrm{b}} \mathrm{GnRH}$-a group vs IVF group ( $\left.p=0.037\right)$; IVF In vitro fertilisation, ASD Atrial septal defect, FSIQ Full-scale intelligence quotient, $A D H D$ Attention-deficit hyperactivity disorder, ASDs Autism spectrum disorders 
pregnant again after a spontaneous abortion or ectopic pregnancy are summarised in Fig. 2. The individuals were subdivided into three subgroups based on the outcomes of the previous GnRH-a-related spontaneous pregnancy. For the 65 women who had given birth successfully, 17 (26.15\%) desired to have a second child, and 12 spontaneous pregnancies culminated in 11 live births and 1 ectopic pregnancy. All 28 women with previous spontaneous abortions desired to become pregnant again, and 16 succeeded: eight conceived naturally and gave birth, while the other eight became pregnant after IVF, and gave live birth (five) or suffered spontaneous abortion (three). The remaining 17 (94.44\%) women who had experienced ectopic pregnancies chose IVF to attempt reproduction. Ultimately, nine of them gave live birth and two suffered spontaneous abortion.

\section{Discussion}

We investigated the obstetric and repregnancy outcomes in women who inadvertently conceived naturally after being administered GnRH-a during the course of IVF treatments and the neurodevelopmental outcomes of the GnRH-a-exposed children. More than half of the participants gave live birth. The neonatal health outcomes and the incidence of maternal complications in the GnRH-aexposed group were comparable to those of the control groups. Except for one case of ASD, the full-scale intelligence quotient score of the offspring was within the normal range and similar to that of the control group. Most mothers with successful pregnancies and about one-third of the women who had spontaneous abortion were subsequently able to naturally conceive again.

Given that GnRH-a is administered in the mid-luteal phase of the previous cycle to suppress pituitary function during long protocol COS, spontaneous pregnancies with accidental exposure to $\mathrm{GnRH}-\mathrm{a}$ are unavoidable; patients may be reluctant to adopt contraceptive measures during the downregulation period, or may even have been recommended to attempt pregnancy during this period by some reproductive centres. Although $\mathrm{GnRH}$ has multiple extrahypothalamic functions that promote the development and implantation of mammalian embryos, it is possible that temporary alleviation of the couples' infertility-specific anxiety during the pituitary downregulation cycle might assist pregnancy [34].

The positive prognosis of spontaneous pregnancies after exposure to $\mathrm{GnRH}-\mathrm{a}$ at a very early stage has been well substantiated by numerous published reports, accounting for approximately $1 \%$ of long protocol IVF cycles $[9,16]$. This report of 114 cases represents a sizable number of pregnancies involving exposure to GnRH-a and demonstrates the long-term physical as well as neurological outcomes of the related offspring. The incidence of these unexpected pregnancies per cycle was $0.56 \%$ at our centre. For the 114 traceable cases, tubal damage and sperm disorder represented the main causes of infertility, similar to other reports $[9,14]$,

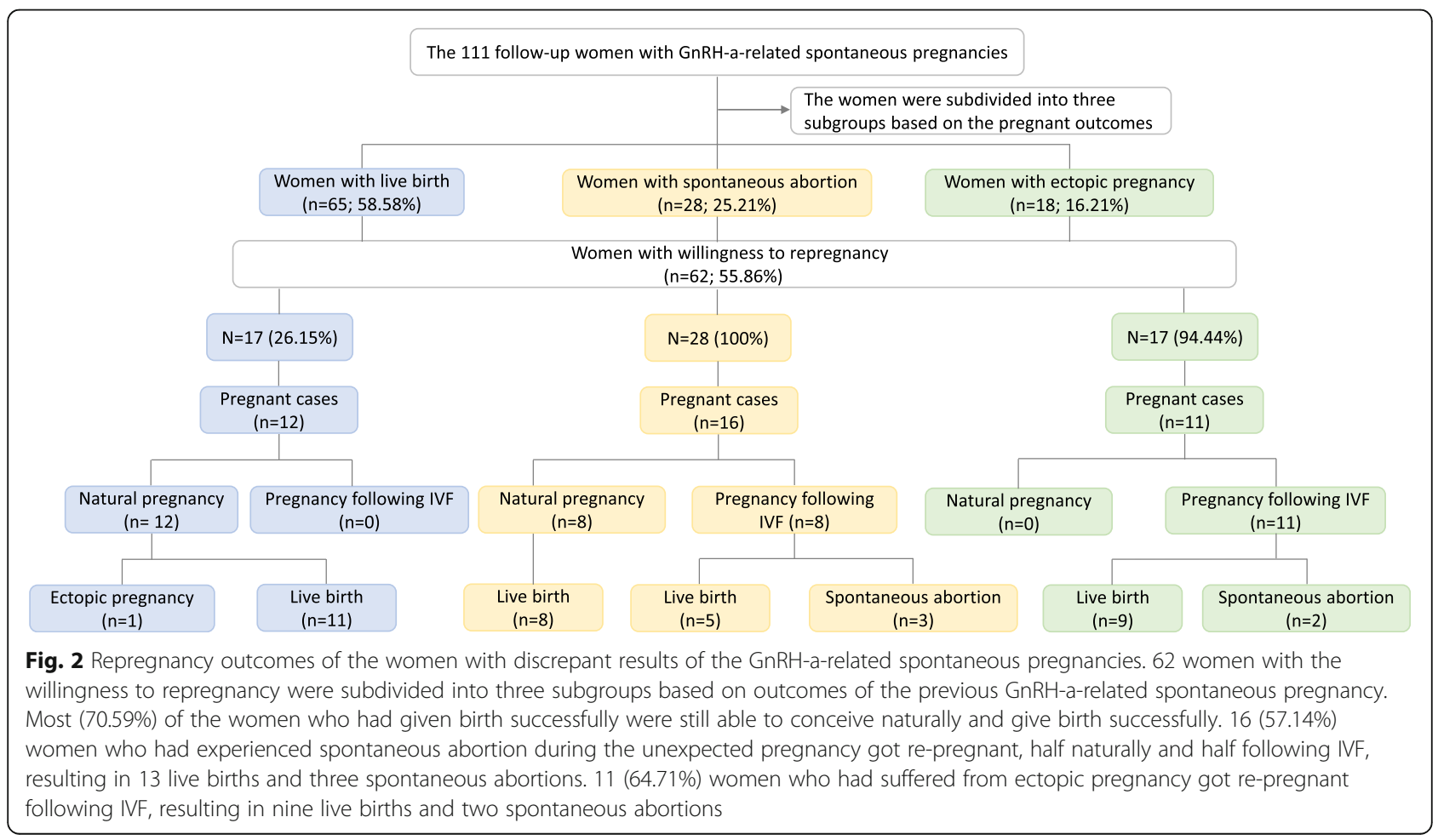


indicating subfertility rather than absolute infertility in these patients. Intramuscular progesterone was routinely applied to correct the probable luteal phase defect caused by the luteolytic properties of GnRH-a [35]; however, the pregnancy loss rate $(40.34 \%)$, including ectopic pregnancies and spontaneous abortions, in our cohort was higher than that of previous studies (around 25\%) [9]. This may be related to the 32 cases in which patients were lost to follow-up. The absence of additional assisted reproductive treatment records for these excluded couples at our centre suggests that these individuals with unexpected pregnancies might have succeeded in having offspring. With these putatively successful cases, the high pregnancy loss rates would be reduced to more typical levels.

Teratogenicity always needs to be considered in these circumstances. In our retrospective analysis of the perinatal characteristics of this large cohort, we confirmed the healthy outcomes of children after inadvertent GnRH-a exposure during early pregnancy. No fatal congenital deformities occurred in any of the 66 children assessed. Two cases of common malformations, including VSD and CL, were identified. These common birth defects are associated with multifactorial origins, such as environmental factors, genetic defects, and maternal features [36]. VSD is the commonest congenital heart defect, with an incidence of approximately 3/1000 in Chinese neonates [37], and spontaneous closure occurs during childhood in most cases [38]. The prevalence rate of CL is around 1/1000 in China [39]. This common malformation is typically effectively repaired by plastic surgery. A large retrospective study in Australia reported two non-fatal malformations, bilateral inguinal hernia and unilateral kidney atresia, in a cohort of 42 children born to mothers with GnRH-a exposure [18]. In addition, the neonatal characteristics of our study group in terms of birth weight, body height, and Apgar score were comparable to those of the IVF and spontaneous delivery groups. Although these favourable neonatal health outcomes could theoretically be explained by the timing of exposure to $\mathrm{GnRH}-\mathrm{a}$ (early pregnancy, a period before organogenesis), further investigation based on a larger cohort is required to elucidate the potential influence of early GnRH-a exposure on foetation outcomes.

Among the various obstetric conditions known to increase the risk of maternal morbidity, multiple pregnancies and advanced maternal age are universally recognised factors. These confer higher risk of pathological changes with severe effects on the mother $[40,41]$. In our study cohort, no increase in obstetric complications of any sort was observed. It is tempting to speculate that short-term administration of GnRH-a in the early stage of pregnancy may not have any effect on maternal complications. Nevertheless, the young age of the couples and the prevalence of singleton pregnancies in the study group may have influenced the favourable obstetric outcomes. Furthermore, the sample size in the current study was insufficient for drawing definite conclusions.

Long-term neurodevelopment data on GnRH-aexposed children is scarce. Lahat et al. [33] reported the long-term neurodevelopment outcomes of six GnRH-aexposed children aged 3-9 years. Four of the six physically healthy children were diagnosed with ADHD, which could have been missed at an earlier assessment. This finding emphasises the importance of a long-term follow-up survey for these affected children. We investigated the intelligence and neurological development of 31 children who were inadvertently exposed to GnRH-a, and only one case of ASD was identified. For the other children, the general cognitive status was within the normal range, and their FSIQ scores were similar to those of the IVF-conceived and naturally conceived children. ASD, a neurological disorder characterised by impaired social communication and stereotypic behaviour, occurs in about $1 \%$ of the population. Genetic, epigenetic, and environmental factors are hypothesised to be associated with this disorder [42]. Interestingly, we found three cases of ADHD in the control groups. ADHD is another neurological disorder that also typically has an onset in childhood, with a prevalence of 3\% [43]. These observations highlight the complexity of the aetiologies of these common neurodevelopmental disorders, suggesting the potentially causative association with obstetric factors, rather than with $\mathrm{GnRH}-\mathrm{a}$ per se. Although the current results further reaffirm the previous proposal that accidental GnRH-a exposure in early pregnancy might be safe [18], a worldwide central registry of GnRH-a exposed pregnancies is urgently needed.

Guidelines for repregnancy in women with GnRH-a exposed pregnancy are currently lacking due to the absence of reliable evidence. We investigated the repregnancy outcomes of the women who had had various outcomes after their previous unexpected pregnancies. Most of the mothers who were desirous of repregnancy were able to conceive naturally and give birth successfully. Nearly half of the individuals who experienced spontaneous abortion during the unexpected pregnancy subsequently gave live birth. Notably, most of these pregnancies were established naturally. In cases with ectopic pregnancy, the couples clearly preferred IVF for repregnancy, and favourable outcomes were consistently achieved with this technique. Our retrospective analysis provides a basis for appropriate counselling and reproductive treatment suggestions for repregnancy in the affected couples.

\section{Conclusions}

There is currently no indication of adverse effects subsequent to inadvertent $\mathrm{GnRH}$-a exposure during the early pregnancy period. Such results have been reasonably 
consistent across geographical regions. Whether these consistent observations justify the recommendation for avoiding contraception during GnRH-a-related pituitary downregulation or utilisation of GnRH-a for promoting IVF success during embryo transfer is not completely clear and requires further specific studies. The reproductive treatment suggestions for repregnancy in women who have become pregnant during GnRH-a administration should take into consideration the specific outcomes of the previous unexpected pregnancy.

\section{Abbreviations}

GnRH-a: Gonadotropin-releasing hormone agonist; COS: Controlled ovarian stimulation; IVF: In vitro fertilisation; HCG: Human chorionic gonadotropin; RSA: Recurrent spontaneous abortion; FSIQ: Full-Scale Intelligent Quotient; ADHD: Attention-deficit hyperactivity disorder; VSD: Ventricular septal defect; CL: Cleft lip

\section{Supplementary Information}

The online version contains supplementary material available at https://doi. org/10.1186/s12958-021-00732-1.

Additional file 1: Table S1. Clinical characteristics of the enrolled couples exposed to $\mathrm{GnRH}$-a soon after conception. Table S2. Maternal complications of the women with live birth inadvertently exposed to GnRH-a. Table S3. Neonatal characteristics of the 66 children born after exposure to $\mathrm{GnRH}$-a. Figure S1. The number of annual $\mathrm{GnRH}$-a long protocol-associated IVF cycles and the corresponding spontaneously conceived cases from 2003 to 2019.

\section{Acknowledgments}

We would like to thank all the patients who agreed to participate in this study.

\section{Authors' contributions}

HW, XX and CM designed the study and drafted the manuscript. XX and SP performed physical and neurodevelopmental evaluation for all the involved children. YZ, HG and YH analyzed the data. QX, YX, PZ and ZW collected the data. YC, XF and XH designed the study and edited the manuscript. All authors read and approved the final manuscript.

\section{Funding}

This work was supported by the National Key R\&D Program of China (Nos. 2019YFC1005106, 2016YFC1000200, and 2016YFC10002004), University Synergy Innovation Program of Anhui Province (No. GXXT-2019-044), and the Non-profit Central Research Institute Fund of Chinese Academy of Medical Sciences (No. 2019PT310002).

\section{Availability of data and materials}

The datasets used and/or analysed during the current study are available from the corresponding author on reasonable request.

\section{Declarations}

Ethics approval and consent to participate

All procedures performed in studies involving humans were in accordance with the ethical standards of the institution or practice at which studies were conducted (Institutional Ethical Committee of the Anhui Medical University, No.20160270)

\section{Consent for publication}

All patients gave written informed consent for publication.

\section{Competing interests}

The authors declare that they have no competing interests.

\section{Author details}

'Reproductive Medicine Center, Department of Obstetrics and Gynecology, The First Affiliated Hospital of Anhui Medical University, No. 218 Jixi Road, Hefei 230022, China. ${ }^{2} \mathrm{NHC}$ Key Laboratory of Study on Abnormal Gametes and Reproductive Tract, Anhui Medical University, No. 81 Meishan Road, Hefei 230032, China. ${ }^{3}$ Key Laboratory of Population Health Across Life Cycle, Anhui Medical University, Ministry of Education of the People's Republic of China, No. 81 Meishan Road, Hefei 230032, China. ${ }^{4}$ The Children's

Neurorehabilitation Center, Pediatric Department, The First Affiliated Hospital of Anhui Medical University, No. 218 Jixi Road, Hefei 230022, China. ${ }^{5}$ Anhui Province Key Laboratory of Reproductive Health and Genetics, No. 81 Meishan Road, Hefei 230032, China. ${ }^{6}$ Biopreservation and Artificial Organs, Anhui Provincial Engineering Research Center, Anhui Medical University, No. 81 Meishan Road, Hefei 230032, China.

Received: 14 December 2020 Accepted: 15 March 2021

Published online: 20 March 2021

\section{References}

1. Siristatidis CS, Gibreel A, Basios G, Maheshwari A, Bhattacharya S. Gonadotrophin-releasing hormone agonist protocols for pituitary suppression in assisted reproduction. Cochrane Database Syst Rev. 2015: CD006919. https://doi.org/10.1002/14651858.CD006919.pub4.

2. Conn PM, Crowley WF. Gonadotropin-releasing hormone and its analogues. N Engl J Med. 1991;324(2):93-103. https://doi.org/10.1056/NEJM199101103240205.

3. Dada T, Salha O, Baillie HS, Sharma V. A comparison of three gonadotrophin-releasing hormone analogues in an in-vitro fertilization programme: a prospective randomized study. Hum Reprod. 1999;14(2):28893. https://doi.org/10.1093/humrep/14.2.288.

4. Maheshwari A, Gibreel A, Siristatidis CS, Bhattacharya S. Gonadotrophinreleasing hormone agonist protocols for pituitary suppression in assisted reproduction. Cochrane Database Syst Rev. 2011:CD006919. https://doi.org/1 0.1002/14651858.CD006919.pub3.

5. Porter RN, Smith W, Craft IL, Abdulwahid NA, Jacobs HS. Induction of ovulation for in-vitro fertilisation using buserelin and gonadotropins. Lancet. 1984;2(8414):1284-5. https://doi.org/10.1016/s0140-6736(84)92840-x.

6. Fleming R, Coutts JR. Induction of multiple follicular growth in normally menstruating women with endogenous gonadotropin suppression. Fertil Steril. 1986;45(2):226-30. https://doi.org/10.1016/S0015-0282(16)49159-4.

7. Testart J, Lefevre B, Gougeon A. Effects of gonadotrophin-releasing hormone agonists (GnRHa) on follicle and oocyte quality. Hum Reprod. 1993;8(4):511-8. https://doi.org/10.1093/oxfordjournals.humrep.a138086.

8. Ron-El R, Herman A, Golan A, van der Ven H, Caspi E, Diedrich K. The comparison of early follicular and midluteal administration of long-acting gonadotropin-releasing hormone agonist. Fertil Steril. 1990;54(2):233-7. https://doi.org/10.1016/S0015-0282(16)53695-4.

9. Cahill DJ, Fountain SA, Fox R, Fleming CF, Brinsden PR, Hull MG. Outcome of inadvertent administration of a gonadotrophin-releasing hormone agonist (buserelin) in early pregnancy. Hum Reprod. 1994;9(7):1243-6. https://doi.org/10.1093/oxfordjournals.humrep.a138686.

10. Elefant E, Biour B, Blumberg-Tick J, Roux C, Thomas F. Administration of a gonadotropin-releasing hormone agonist during pregnancy: follow-up of 28 pregnancies exposed to triptoreline. Fertil Steril. 1995;63(5):1111-3. https:// doi.org/10.1016/50015-0282(16)57557-8.

11. Platteau P, Gabbe M, Talbot M, Healy D. Two consecutive pregnancies during inadvertent gonadotropin-releasing hormone agonist desensitization. Fertil Steril. 2000;73(6):1244-6. https://doi.org/10.1016/50015-0282(00)00536-7.

12. Tan HH, Yeong $C T$, Loh KE. Perinatal outcome of pregnancies after inadvertent exposure to gonadotrophin-releasing hormone analogue. Aust N Z J Obstet Gynaecol. 2006;46(4):336-40. https://doi.org/10.1111/j.1479-828X.2006.00602x.

13. Wilshire GB, Emmi AM, Gagliardi CC, Weiss G. Gonadotropin-releasing hormone agonist administration in early human pregnancy is associated with normal outcomes. Fertil Steril. 1993;60(6):980-3. https://doi.org/10.101 6/S0015-0282(16)56396-1.

14. Har-Toov J, Brenner SH, Jaffa A, Yavetz H, Peyser MR, Lessing JB. Pregnancy during long-term gonadotropin-releasing hormone agonist therapy associated with clinical pseudomenopause. Fertil Steril. 1993;59(2):446-7. https://doi.org/10.1016/S0015-0282(16)55702-1.

15. Gartner B, Moreno C, Marinaro A, Remohi J, Simon C, Pellicer A. Accidental exposure to daily long-acting gonadotrophin-releasing hormone analogue 
administration and pregnancy in an in-vitro fertilization cycle. Hum Reprod. 1997;12(11):2557-9. https://doi.org/10.1093/humrep/12.11.2557.

16. Balasch J, Martinez F, Jove I, Cabre L, Coroleu B, Barri PN, Vanrell JA. Inadvertent gonadotrophin-releasing hormone agonist ( $\mathrm{GnRHa}$ ) administration in the luteal phase may improve fecundity in in-vitro fertilization patients. Hum Reprod. 1993;8(7):1148-51. https://doi.org/10.1 093/oxfordjournals.humrep.a138210.

17. Smitz J, Camus M, Devroey P, Bollen N, Tournaye H, Van Steirteghem AC. The influence of inadvertent intranasal buserelin administration in early pregnancy. Hum Reprod. 1991;6(2):290-3. https://doi.org/10.1093/ oxfordjournals.humrep.a137324

18. Platteau P, Gabbe M, Famelos M, Kovacs G, Healy D. Should we still advise infertile couples to use (barrier) contraception before IVF down-regulation? Fertil Steril. 2000;74(4):655-9. https://doi.org/10.1016/S0015-0282(00)01524-7.

19. Papanikolaou EG, Platteau P, Albano C, Kolibianakis E, Devroey P. Achievement of pregnancy three times in the same patient during luteal GnRH agonist administration. Reprod BioMed Online. 2005;10(3):347-9. https://doi.org/10.1016/S1472-6483(10)61794-4.

20. Tesarik J, Hazout A, Mendoza C. Enhancement of embryo developmental potential by a single administration of $\mathrm{GnRH}$ agonist at the time of implantation. Hum Reprod. 2004;19(5):1176-80. https:/doi.org/10.1093/humrep/deh235.

21. Kawamura K, Fukuda J, Kumagai J, Shimizu Y, Kodama H, Nakamura A, Tanaka T. Gonadotropin-releasing hormone I analog acts as an antiapoptotic factor in mouse blastocysts. Endocrinology. 2005;146(9):410516. https://doi.org/10.1210/en.2004-1646.

22. Kanter M, Sapmaz-Metin M, Serez B. Effects of GnRHa on early embryonic development in mice receiving cyclophosphamide. Arch Gynecol Obstet. 2016;293(1):203-9. https://doi.org/10.1007/s00404-015-3831-x.

23. Peng B, Zhu H, Leung PC. Gonadotropin-releasing hormone regulates human trophoblastic cell invasion via TWIST-induced N-cadherin expression. J Clin Endocrinol Metab. 2015;100(1):E19-29. https:/doi.org/10.1210/jc.2014-1897.

24. Peng B, Zhu H, Klausen C, Ma L, Wang YL, Leung PC. GnRH regulates trophoblast invasion via RUNX2-mediated MMP2/9 expression. Mol Hum Reprod. 2016;22(2):119-29. https://doi.org/10.1093/molehr/gav070.

25. Lin LS, Roberts VJ, Yen SS. Expression of human gonadotropin-releasing hormone receptor gene in the placenta and its functional relationship to human chorionic gonadotropin secretion. J Clin Endocrinol Metab. 1995; 80(2):580-5. https://doi.org/10.1210/jcem.80.2.7852524.

26. Lee HJ, Snegovskikh W, Park JS, Foyouzi N, Han KT, Hodgson EJ, Guller S, Norwitz ER. Norwitz ER. Role of GnRH-GnRH receptor signaling at the maternal-fetal interface. Fertil Steril. 2010;94(7):2680-7. https://doi.org/10.101 6/j.fertnstert.2010.03.016

27. Oride A, Kanasaki H, Mijiddorj T, Sukhbaatar U, Ishihara T, Kyo S. Regulation of kisspeptin and gonadotropin-releasing hormone expression in rat placenta: study using primary cultures of rat placental cells. Reprod Biol Endocrinol. 2015;13(1):90. https://doi.org/10.1186/s12958-015-0083-3.

28. Paria BC, Reese J, Das SK, Dey SK. Deciphering the cross-talk of implantation: advances and challenges. Science. 2002;296(5576):2185-8. https://doi.org/1 $0.1126 /$ science.1071601.

29. Chou CS, MacCalman CD, Leung PC. Differential effects of gonadotropin-releasing hormone I and II on the urokinase-type plasminogen activator/plasminogen activator inhibitor system in human decidual stromal cells in vitro. J Clin Endocrinol Metab. 2003;88(8):3806-15. https://doi.org/10.1210/jc.2002-021955.

30. Isik AZ, Caglar GS, Sozen E, Akarsu C, Tuncay G, Ozbicer T, Vicdan K. Singledose $\mathrm{GnRH}$ agonist administration in the luteal phase of $\mathrm{GnRH}$ antagonist cycles: a prospective randomized study. Reprod BioMed Online. 2009;19(4): 472-7. https://doi.org/10.1016/j.rbmo.2009.04.001.

31. Tesarik J, Hazout A, Mendoza-Tesarik R, Mendoza N, Mendoza C. Beneficial effect of luteal-phase GnRH agonist administration on embryo implantation after ICSI in both GnRH agonist- and antagonist-treated ovarian stimulation cycles. Hum Reprod. 2006;21(10):2572-9. https://doi.org/10.1093/humrep/del173.

32. Martins WP, Ferriani RA, Navarro PA, Nastri CO. GnRH agonist during luteal phase in women undergoing assisted reproductive techniques: systematic review and meta-analysis of randomized controlled trials. Ultrasound Obstet Gynecol. 2016;47(2):144-51. https://doi.org/10.1002/uog.14874.

33. Lahat E, Raziel A, Friedler S, Schieber-Kazir M, Ron-El R. Long-term follow-up of children born after inadvertent administration of a gonadotrophinreleasing hormone agonist in early pregnancy. Hum Reprod. 1999;14(10): 2656-60. https://doi.org/10.1093/humrep/14.10.2656.

34. Rooney KL, Domar AD. The relationship between stress and infertility. Dialogues Clin Neurosci. 2018;20:41-7.
35. Tannus S, Burke Y, McCartney CR, Kol S. GnRH-agonist triggering for final oocyte maturation in GnRH-antagonist IVF cycles induces decreased LH pulse rate and amplitude in early luteal phase: a possible luteolysis mechanism. Gynecol Endocrinol. 2017;33(9):741-5. https://doi.org/10.1080/ 09513590.2017.1318275.

36. Hobbs CA, Chowdhury S, Cleves MA, Erickson S, MacLeod SL, Shaw GM, Tycko B, et al. Genetic epidemiology and nonsyndromic structural birth defects: from candidate genes to epigenetics. JAMA Pediatr. 2014;168(4): 371-7. https://doi.org/10.1001/jamapediatrics.2013.4858.

37. Zhao QM, Liu F, Wu L, Ma XJ, Niu C, Huang GY. Prevalence of congenital heart disease at live birth in China. J Pediatr. 2019;204:53-8. https://doi.org/1 0.1016/j.jpeds.2018.08.040.

38. Zhao QM, Niu C, Liu F, Wu L, Ma XJ, Huang GY. Spontaneous closure rates of ventricular septal defects (6,750 consecutive neonates). Am J Cardiol. 2019;124(4):613-7. https://doi.org/10.1016/j.amjcard.2019.05.022.

39. Wang M, Meng R, Wang Z, Liu D, Huang H, Kang C, Zhan S, et al. Prevalence of oral clefts among live births in Gansu Province, China. Int J Environ Res Public Health. 2018;15(2):380.

40. Santana DS, Silveira C, Costa ML, Souza RT, Surita FG, Souza JP, Sousa MH, et al. Perinatal outcomes in twin pregnancies complicated by maternal morbidity: evidence from the WHO Multicountry Survey on Maternal and Newborn Health. BMC Pregnancy Childbirth. 2018;18(1):1.

41. Sauer MV. Reproduction at an advanced maternal age and maternal health. Fertil Steril. 2015;103(5):1136-43. https://doi.org/10.1016/j.fertnstert.2015.03.004.

42. Muotri AR. Autism spectrum disorders: challenges and perspectives. Dev Neurobiol. 2018;78(5):431-3. https://doi.org/10.1002/dneu.22586.

43. Thapar A, Cooper M. Attention deficit hyperactivity disorder. Lancet. 2016; 387(10024):1240-50. https://doi.org/10.1016/S0140-6736(15)00238-X.

\section{Publisher's Note}

Springer Nature remains neutral with regard to jurisdictional claims in published maps and institutional affiliations.

Ready to submit your research? Choose BMC and benefit from:

- fast, convenient online submission

- thorough peer review by experienced researchers in your field

- rapid publication on acceptance

- support for research data, including large and complex data types

- gold Open Access which fosters wider collaboration and increased citations

- maximum visibility for your research: over $100 \mathrm{M}$ website views per year

At BMC, research is always in progress.

Learn more biomedcentral.com/submissions 